\title{
INTERAÇÃO UNIVERSIDADE E ESCOLA: O ESTÁGIO SUPERVISIONADO COMO POSSIBILIDADE DE UMA PRÁTICA TRANSDISCIPLINAR
}

\author{
Berenice Feitosa da Costa Aires ${ }^{\mathrm{i}}$ \\ Universidade Federal de Tocantins (Brasil) \\ João Henrique Suanno \\ Universidade Estadual de Goiás (Brasil)
}

\begin{abstract}
Resumo. Este artigo visa apresentar e discutir os resultados de um trabalho inovador, desenvolvido no Projeto de Extensão Interação Universidade e Escola, vinculado ao Estágio Curricular do Curso de Pedagogia da Universidade Federal do Tocantins (UFT), aplicado na Escola Municipal Benedita Galvão, em Palmas, Tocantins. Para a análise dos discursos que impregnam as práticas interdisciplinares, desenvolvidas no ano de 2016, foram realizadas entrevistas com grupos focais, compostos por estagiárias do Curso de Pedagogia-UFT, e feita a análise documental dos relatórios finais de estágio que apresentam os resultados das práticas aplicadas no projeto de Interação Universidade e Escola. Baseamos a nossa argumentação nas teorias e propostas paradigmáticas dos seguintes autores: Pimenta (2004), Morin (2000, 2001, 2007, 2009, 2011, 2015), Suanno, J. H. (2013a, 20013b, 2015a, 2015b), Suanno, M.V.R. (2014, 2015), Moraes (2008), Torre $(2005,2012)$ e outros. Pretendeu-se problematizar como o processo formativo de professores articula pensamento complexo, interdisciplinaridade e transdisciplinaridade na ação das estagiárias nas práticas pedagógicas das atividades de estágio curricular nos anos iniciais do Ensino Fundamental. Constatou-se que os entrevistados consideram relevante a inserção de Estágio Curricular por meio de Projetos de Extensão que promovam a articulação entre Escola e Universidade, vinculando formação inicial e continuada no desenvolvimento de suas ações.
\end{abstract}

Palavras-chave: Formação de professores, práticas interdisciplinares, estágio supervisionado.

\section{INTERACTION BETWEEN UNIVERSITY AND SCHOOL: THE SUPERVISED PRACTICE AS A POSSIBILITY OF TRANSDISCIPLINARY PRACTICE}

\begin{abstract}
This article aims to present and discuss the results of an innovative work developed in the Project of Extension Interaction University and School, linked to the Curricular Internship of the Pedagogy course of the Federal University of Tocantins (UFT) applied at the Benedita Galvão Municipal School in Palmas, Tocantins. For the analysis of the speeches that permeate the Interdisciplinary practices developed in 2016, interviews were conducted with focus groups composed of trainees from the Pedagogy-UFT course and the documentary analysis of the final internship reports that present the results of the practices applied in the project of Interaction University and School. We base our argument on the theories and paradigmatic proposals of the following authors: Pimenta (1991), Morin (2000, 2001, 2007, 2009, 2011, 2015), Suanno, JH (2012, 2014, 2015), Suanno MVR (2014, 2015a, 2015b), Moraes (2008, $2015)$, Torre $(2005,2008)$ and others. It was intended to problematize how the formative process of teachers articulates complex thinking, interdisciplinarity and transdisciplinarity in the action of the trainees in the pedagogical practices of the activities of curricular internship in the initial years of Elementary School. It was verified that the interviewees consider the insertion of Curricular Internship through Extension Projects that promote the articulation between School and University, articulating initial and continued formation with the development of Curricular Internship actions.
\end{abstract}


Keywords: teacher training, interdisciplinary practices, supervised internship.

\title{
INTERACCIÓN UNIVERSIDAD Y ESCUELA: LA PASANTÍA SUPERVISADA COMO POSIBILIDAD DE UNA PRÁCTICA TRANSDISCIPLINARIA
}

\begin{abstract}
Resumen. Este artículo se propone presentar y discutir los resultados de un trabajo innovador, desarrollado bajo el contexto del Proyecto de Extensión Interacción Universidad y Escuela, el cual se encuentra vinculado a la Pasantía Curricular de la Carrera de Pedagogía de la Universidad Federal de Tocantins (UFT). Ese proyecto de extensión fue llevado a cabo en la Escuela Municipal Benedita Galvão, en Palmas, la capital del estado brasileño de Tocantins. Para el análisis de los discursos que impregnan las prácticas interdisciplinarias desarrolladas en 2016, se realizaron entrevistas con grupos focales, compuestos por pasantes de la Carrera de Pedagogía-UFT. Además, se realizó el análisis documental de los informes finales de pasantía, los cuales presentan los resultados de las prácticas aplicadas en el proyecto de Interacción Universidad y Escuela. Nuestra argumentación se basa en las teorías y propuestas paradigmáticas de los siguientes autores: Pimenta (2004), Morin (2000, 2001, 2007, 2009, 2011, 2015), Suanno, J. H. (2013a, 20013b, 2015a, 2015b), Suanno, M.V.R. (2014, 2015), Moraes (2008), Torre (2005, 2012), entre otros. La idea central fue problematizar cómo el proceso formativo de los profesores realiza la articulación entre pensamiento complejo, interdisciplinariedad y transdisciplinariedad, en las acciones de las pasantes en las prácticas pedagógicas de las actividades de pasantía curricular en los primeros años de la Escuela Primaria. Se constató que los entrevistados consideran relevante la inserción de la Pasantía Curricular por medio de Proyectos de Extensión que fomenten la articulación entre Escuela y Universidad, vinculando formación inicial y continuada en el desarrollo de sus acciones.
\end{abstract}

Palabras clave: Formación de profesores, prácticas interdisciplinarias, pasantía supervisada.

\section{Introdução}

O presente artigo apresenta os resultados de uma experiência formativa colocada em prática no Estágio Curricular do Curso de Pedagogia da Universidade Federal do Tocantins (UFT). Trata-se do Projeto de Extensão Interação Universidade e Escola, que viabiliza a articulação entre ensino, pesquisa e extensão. Projetos de Ensino Interdisciplinar são executados para o desenvolvimento de atividades do estágio curricular no âmbito do curso de Pedagogia e a formação continuada dos professores da Escola Municipal Benedita Galvão, em Palmas, Tocantins (TO), Brasil. Para tanto, foi firmado convênio com a Universidade Federal de Tocantins (UFT), que se tornou o campo de estágio de um grupo de alunas do quarto ano do Curso de Pedagogia durante o ano de 2016. Com um grupo gestor bastante receptivo e aberto para esse trabalho de parceria, a escola mostrou-se em sua inteireza, permitindo às estagiárias e à professora orientadora trocar ideias, traçar metas e construir, coletivamente, momentos e experiências de aprendizagem.

O estágio oferece:

“... a fundamentação teórica necessária para a articulação com a prática e a crítica criativa do professor em relação ao aluno, à escola e à sociedade" (Lima, 2012, p. 55). 
Uma prática crítica e criativa que, em nosso entendimento, não poderá prescindir de um enfoque transdisciplinar, na medida em que reconhece:

“... a necessidade de uma educação para a paz, para o desenvolvimento sustentável, para a convivência amorosa e plena de sentido nos ambientes educativos." (Arnt, 2012, p. 180).

A transdisciplinaridade propõe a investigação e:

"... a compreensão da realidade com base na integração das ciências, das artes, das tradições, indo além das disciplinas." (Arnt, 2012, p. 180), construindo um pensamento que, com esforço e risco, considere a diversidade do real (Morin, 2000). Nesse sentido, “ nosso pensamento não poderá mais se fechar em compartimentos estanques, não poderá mais ser simplificador e reducionista, mas passará a ter uma visão ampliada e complexa dos sistemas, das organizações, dos processos e, como consequência, novos caminhos poderão construir uma forma de intervenção transdisciplinar." (Melo, 2011, p. 111).

Mas, para sair do papel ou da retórica, a construção de uma intervenção transdisciplinar exige um movimento concreto entre os sujeitos, no reconhecimento e na troca, no planejamento e na ação, para, efetivamente, caminharem e abrirem os espaços e tempos necessários à integração. A transdisciplinaridade demanda o reconhecimento e a abertura ao outro, requer a criação e manutenção de espaços coletivos. Assim as ações teórico-práticas do estágio, realizado na Escola Municipal Benedita Galvão, foram pensadas a partir de momentos de estudo, reflexão, pesquisa e planejamento. Momentos de estudo para compreensão dos objetivos e da concepção do estágio como pesquisa e investigação, para compreensão da interdisciplinaridade e transdisciplinaridade como fundamentação da ação e para compreensão das dimensões sociais, institucionais, econômicas e culturais.

Os projetos interdisciplinares são elaborados com base na perspectiva do pensamento complexo, como descreve Morin (2001, p. 10):

“... o pensamento complexo é animado por uma tensão permanente entre a aspiração a um saber não parcelar, não fechado, não redutor e o reconhecimento do inacabamento, da incompletude de todo o conhecimento".

Diante dessa sustentação complexa, a perspectiva transdisciplinar contribui para que esse conhecimento, ao invés de fragmentado, seja interligado, unido. Segundo ainda Morin (2007, p. 25):

“... para ser transdisciplinar é preciso ter um conhecimento complexo. Não se pode ser transdisciplinar apenas justapondo elementos. É preciso saber ligar os elementos das diferentes disciplinas." 
Ou seja, com base na compreensão de que a realidade é multidimensional e multirreferencial, apresentando-se em diversos aspectos, obter-se-ão consciência complexa e saber transdisciplinar para religar o que a concepção simplificadora separou.

Assim, o pensar complexo é um pensamento capaz de unir conceitos que divergem entre si, de modo a promover o pensamento articulado, religando razão, emoção, corporeidade, conhecimentos, saberes populares, em um modo de pensar multidimensional (múltiplas dimensões no objeto de pesquisa), multirreferencial (diferentes e múltiplos referenciais teóricos no processo de construção do conhecimento) e autorreferencial (que se refere a si próprio; autopoiese).

Os vários momentos de estudo e reflexão ocorreram em todas as fases do estágio. Ou seja, permearam os momentos de pesquisa documental na escola-campo, os momentos de observação em sala de aula e os momentos de regência. Como resultado desses estudos, os grupos de estágio elaboraram os Projetos Interdisciplinares a serem executados na Escola Municipal Benedita Galvão na cidade de Palmas, TO.

O estágio do curso de Pedagogia da UFT/Câmpus Palmas na Escola Municipal Benedita Galvão tem tido por base uma relação de parceria e amizade entre universidade, escola e comunidade. Envolve formação continuada de professores e gestores escolares em um projeto de trabalho com a comunidade escolar no intuito de impulsionar ações e práticas transdisciplinares e interdisciplinares. As ações foram criadas em um ambiente de corresponsabilidade, respeito e alegria de juntos possibilitar novas concepções e ações para a vida escolar, a vida universitária e para a aprendizagem das crianças, dos estagiários, dos professores.

O projeto de formação continuada desenvolvido na parceria UniversidadeEscola é concebido no âmbito de formação, como resultado da ação institucional. Assim o conceito de formação de professores está sujeito à ideia ou à representação sobre o que é ser professor e sua prática docente. Por conseguinte, a concepção de formação é definida como um contínuo de ações que visam ao desenvolvimento profissional e contribuem para a ressignificação dos espaços de aprendizagem, tendo em vista a formação do sujeito ativo, reflexivo e participativo.

Os Projetos Interdisciplinares de ações do Estágio Curricular do curso de Pedagogia (UFT) buscam romper com a fragmentação do conhecimento disciplinar, religando os conhecimentos, as emoções e as visões de mundo. Para isso, consideram a reflexão produzida nas ações de ensino (estágio) e extensão, centrando-se na problematização para a compreensão do tema e a construção de conceitos. O objetivo é produzir conhecimentos, promover a reforma do pensamento e ampliar a consciência dos educandos dos anos iniciais do Ensino Fundamental e das estagiárias sobre si, bem como metodologias de ensino e aprendizagem para formação continuada dos professores da escola-campo.

Os Projetos Interdisciplinares são elaborados na concepção de Estágio Supervisionado, conforme Suanno (2015, p. 141):

... estágio, na formação de professores, é uma disciplina de caráter teóricovivencial desenvolvido por meio da apreensão, problematização e pesquisa sobre a realidade escolar, os processos de ensino, a aprendizagem dos alunos, as especificidades da organização e gestão da escola, e fundamentalmente possibilita ao(à) estagiário(a) se perceber e se experimentar como professor. 
Tal concepção de estágio emerge, pois, da noção de educação como processo dialético de desenvolvimento individual, social, antropológico, um enfoque multidimensional do humano, em sua relação com o caráter coletivo da docência.

Os Projetos Interdisciplinares de ações do Estágio Curricular do curso de Pedagogia (UFT) buscam romper com a fragmentação do conhecimento disciplinar, religando os conhecimentos, as emoções e as visões de mundo. Para isso, consideram a reflexão produzida nas ações de ensino (estágio) e extensão, centrando-se na problematização para a compreensão do tema e a construção de conceitos. O objetivo é produzir conhecimentos, promover a reforma do pensamento e ampliar a consciência dos educandos dos anos iniciais do Ensino Fundamental e das estagiárias sobre si, bem como metodologias de ensino e aprendizagem para formação continuada dos professores da escola-campo.

Também, consideram o pensar complexo, o que implica organizar o conhecimento, religando saberes de diferentes disciplinas e áreas do conhecimento. Vale-se de sua articulação com os saberes populares, estéticos e culturais, resultando no trabalho com temas ministrados interdisciplinarmente com todas as disciplinas, no intuito de ligar razão, emoção e atitude transformadora. Considera-se a transdisciplinaridade como um conjunto de ações que na sua realização auxiliam a superação de atitudes das pessoas em prol de uma construção consciente de novas situações que se coadunam com as necessidades humanas e planetárias no século XXI e nos vindouros.

Trata-se de projetos que consideram também a concepção de sociedade, cuja transformação, segundo Morin (2011), passa pela educação, por ele nomeada de reforma do pensamento, que é justamente essa mudança de pensamento de estruturação da vida. O propósito é possibilitar o pensar complexo e a instauração de bases para uma reforma política que visa ser capaz de fomentar: política de qualidade de vida, política de convivência, política ecológica, política de solidariedade, por meio da cidadania e da sustentabilidade planetárias.

Assim, a compreensão do ser humano está baseada na epistemologia da complexidade, em que o ser humano, na sua capacidade de pensar complexo, é compreendido, além de ser biológico, também como um ser histórico, social e cultural, a fim de buscar compreender uma realidade que não é dicotomizada - ela é multidimensional e complexa.

Esses projetos transdisciplinares fundamentam a prática docente no ensinar a viver (Morin, 2015), ou seja, contribuem para que o estudante aprenda a viver ou pelo menos busque ampliar o sentido da vida, da existência humana. Segundo Morin (2015), para que ocorra a aprendizagem é necessário expandir o horizonte do educando, gerando oportunidades que possibilitem experiências, vivências geradoras de aprendizagem. O professor deve ajudar nesse processo, isto é, “introduzir na preocupação pedagógica o viver bem, o saber viver, a arte de viver para transformar o sujeito e a sociedade" (Morin, 2015, p. 30).

A importância da pesquisa está no estágio curricular do curso de Pedagogia, que, como campo de conhecimento pedagógico, tem despertado o interesse e a atenção de estudiosos e pesquisadores da área da educação. Refere-se a um campo teórico que produz, na interação das práticas formativas que ocorrem na universidade e escola. Vale lembrar que o egresso desse curso tem como foco a docência e a gestão na educação, cuja responsabilidade é a de promover ações pedagógicas voltadas para os anos iniciais do Ensino Fundamental da Educação Básica. Além disso, porque há a necessidade de 
ampliação do debate acerca da qualidade das práticas pedagógicas desenvolvidas na educação básica, como componente de uma cidadania abrangente. Esta relaciona-se a uma nova forma de relação ser humano-natureza-sociedade, baseada numa ética que pressupõe outros valores morais e uma forma diferente de ver o mundo e os homens.

A trajetória da formação de professores demonstra a gradativa ampliação do debate no meio educacional, principalmente no que diz respeito à formação inicial de professores Contudo, ainda hoje, encontram-se práticas nas quais o estágio supervisionado, segundo Pimenta e Lima (2004), é considerado a prática dos cursos de formação de profissionais, ou seja, momento de aplicação de teorias, funcionando como aglomerado de disciplinas isoladas entre si, sem articular a teoria e a prática, como saberes que se complementam. Denunciam que, para as disciplinas teóricas, há uma carga horária maior do que para as de cunho prático, tornando assim o estágio uma disciplina de caráter técnico e burocrático.

Essa constatação revela a urgência do desenvolvimento de estudos e pesquisas que aprofundem a relação entre Estágio Curricular e Formação Inicial de professores. Nesse sentido cabe à Universidade uma parcela de contribuição nessas novas buscas. Deve-se trabalhar na perspectiva da superação da visão ingênua e reducionista das estagiárias, assumindo uma nova postura, uma redefinição do estágio, para que caminhem na formação docente, tornando o professor um profissional crítico e reflexivo. Com base nas afirmações anteriores, compreende-se que, para que seja vivenciada a dimensão do Estágio Curricular, torna-se fundamental romper com os comportamentos preestabelecidos e estereotipados, o que deve necessariamente ocorrer no processo de formação inicial. Esse é um caminho fundamental para que a dimensão do estágio curricular amplie e solidifique seu espaço nas discussões de formação de professores nos cursos de pedagogia.

Como instância de reflexão da prática pedagógica, o estágio assume lugar de destaque entre os componentes curriculares. Segundo o Parecer $n^{\circ}$ 21/2001, do Conselho Nacional de Educação, o estágio é definido:

Como um tempo de aprendizagem que, através de um período de permanência, alguém se demora em um lugar ou oficio para aprender a prática do mesmo e depois poder exercer uma profissão ou oficio. Assim o estágio supõe uma relação pedagógica entre alguém que já é um profissional reconhecido em um ambiente institucional de trabalho e um aluno estagiário [...] é o momento de efetivar um processo de ensino/aprendizagem que tornar-se-á concreto e autônomo quando da profissionalização. (Brasil, 2002, s. p.).

Desse modo, o estágio apresenta-se como momento de aprendizagem da docência no sentido estrito da palavra, pois propicia o confronto com as orientações de como se deve ser professor. Diz respeito a um aprendizado que se inicia nos primeiros momentos de formação e vai se consolidando ao longo do curso. Torna-se, assim, imprescindível pensar no desafio metodológico interdisciplinar, na reforma do pensamento e da educação propostas por Edgar Morin, a partir do reconhecimento da complexidade e da urgência de um conhecimento transdisciplinar, o que representa 
desafios e rupturas com nossa forma tradicional de pensar e de estruturar o trabalho docente, o currículo e o processo de ensinar e aprender.

Os desafios referem-se à necessidade de romper com conceitos e preconceitos já enraizados em nosso pensar, para, assim, construir ou reconstruir novas formas de ensinar, aprender e conviver.

\section{O método}

Para o alcance do objetivo proposto, optou-se pela pesquisa exploratória, apoiada pela abordagem qualitativa. De acordo com Gil (2002), esse tipo de pesquisa tem como objetivo proporcionar maior familiaridade com o problema, no intuito de torná-lo mais explícito ou constituir hipóteses. Com o propósito fundamental de aprimorar as ideias ou descobrir intuições, seu planejamento é bastante flexível, de modo que são consideradas as mais variadas aparências do fato estudado.

Ainda de acordo com o autor, a referida pesquisa tem como principal finalidade:

... desenvolver, esclarecer e modificar conceitos e ideias, tendo em vista a formulação de problemas mais precisos ou hipóteses pesquisáveis para estudos posteriores. De todos os tipos de pesquisa, estas são as que apresentam menor rigidez no planejamento. Habitualmente envolvem levantamento bibliográfico e documental, entrevistas não padronizadas e estudos de caso. (Gil, 2008, p. 27).

A coleta de dados foi realizada por meio de um levantamento bibliográfico e análises dos relatórios final dos Estágios Curriculares, o que nos permitiu verificar com profundidade as práticas pedagógicas das estagiárias desenvolvidas durante o ano de 2016. Fez-se uso de entrevistas junto à coordenação de Estágio Supervisionado da UFT e à coordenação pedagógica da Escola Municipal Benedita Galvão, com o objetivo de conhecer como as experiências formativas interdisciplinares têm articulado, na formação inicial, o modo de pensar complexo inter/transdisciplinar das estagiárias do curso de Pedagogia da UFT.

As discussões com as estagiárias foram realizadas por intermédio da constituição de um grupo focal, que se configura como sustentáculo para um estudo que serve não somente como diagnóstico de uma realidade, mas como oportunidade de debate e reflexão que pode ser o início de uma transformação. A obtenção de dados corresponde a uma parte da pesquisa, a partir da qual se fornece um aparato preciso de informações e permite tecer considerações relevantes e embasadas. Entretanto, a discussão parece-nos ser a parte mais rica da investigação, pois é por meio dela que são expostas vivências e propostas soluções.

Nas discussões junto às estagiárias, foram foco de análise as experiências inter/transdisciplinares, adquiridas a partir do estágio curricular na formação inicial do pedagogo. 


\section{Resultados e discussões}

Refletir sobre o estágio como componente curricular é pôr em questão a complexa relação que se estabelece entre teoria e prática na formação de professores. Em geral o estágio supervisionado tem sido visto como parte prática dos cursos de licenciatura, ou seja, o tempo-espaço de aplicação de conhecimentos adquiridos durante a formação acadêmica e profissional. Essa visão de estágio encontra-se superada nos projetos de prática e estágio por uma noção que articula ensino com pesquisa, admitindo uma iniciação da prática docente desde os primeiros anos de formação.

O conceito de estágio na formação de professores tem sido objeto de sistematização crítica e propositiva. Os estudiosos que congregam a área temática da Didática e Prática de Ensino concebem o estágio como uma instância de articulação das aprendizagens teóricas e práticas da formação de professores.

Nessa perspectiva, Barreiro e Gebran (2006, p. 20) referem que o estágio pode se:

"... construir no lócus de reflexão e formação da identidade ao propiciar embates no decorrer das ações vivenciadas pelos alunos, desenvolvidas numa perspectiva reflexiva e critica, desde que efetivado com essa finalidade."

O projeto inter/transdisciplinar desenvolvido durante o ano 2016, pelas acadêmicas do Curso de Pedagogia da UFT, na disciplina de Ciências Naturais, oportunizou o diálogo sobre a manutenção da vida na terra e a necessidade de proteção dos recursos hídricos. O tema foi abordado a partir dos conhecimentos prévios dos educandos, com o objetivo de religar conhecimentos de diferentes disciplinas em perspectiva multidimensional e multirreferencial. Valendo-se do tema 'Água', consideraram-se as dimensões regionais, sociais, individuais, naturais e artísticas (poéticas, literatura e musicais).

O projeto inter/transdisciplinar desenvolvido durante o ano 2016, pelas acadêmicas do Curso de Pedagogia da UFT, na disciplina de Ciências Sociais, foi construído em torno do tema "Moradias Sociais" e dos subtemas "democracia, cidadania, consciência, ocupações ilegais, justiça, responsabilidade social, solidariedade, pluralidade cultural, igualdade, diversidade, globalização, cultura de paz e não violência, direitos humanos". Buscou-se estabelecer relações entre esses conteúdos e o cotidiano dos educandos, de modo a desenvolver a capacidade do pensar complexo e, também, a sensibilidade do sujeito para a reflexão sobre as questões humanas, sociais e ambientais. De acordo com Morin (2011, p.29), a articulação das disciplinas em torno de um tema orienta que devemos aprender que a procura da verdade pede e busca a elaboração de pontos de vista. Com base nisso, foi possível garantir a compreensão e a participação dos estudantes a partir dos conhecimentos que possuíam.

Desenvolvido pelas estagiárias do curso de Pedagogia da UFT, na disciplina de Matemática, o projeto inter/transdisciplinar buscou promover uma nova relação com o conhecimento, com a vida e com os estudantes por meio do diálogo e da reflexão em torno dos seguintes temas: multiplicação, o dobro, o triplo, a construção da tabuada e sua importância para o cotidiano dos alunos. Em seguida foi trabalhado com a roleta da 
sabedoria, com vistas à contextualização dos conteúdos abordados com o cotidiano dos alunos.

O projeto inter/transdisciplinar das estagiárias do Curso de Pedagogia da UFT na disciplina de Português buscou, na disciplina de Literatura, apresentar os fundamentos e características da Literatura Infantil, de modo a compreender o seu conceito e suas contribuições para o processo de ensino e aprendizagem. $\mathrm{O}$ intuito foi subsidiar o futuro pedagogo no seu ofício de educar a partir do trabalho com a diversidade das obras literárias voltadas para o público infantil e com os diversos recursos utilizados para atividades envolvendo o imaginário da criança. E na disciplina de História foi utilizada a própria história da Escola como forma de treino para a escrita.

Nas discussões junto às estagiárias, foram foco de análise as práticas e experiências interdisciplinares no estágio curricular adquiridas a partir dos projetos inter/transdisciplinares na formação inicial do pedagogo.

$\mathrm{Na}$ primeira discussão junto ao grupo focal das estagiárias, abordamos a criatividade:

“... considerando que a criatividade por meio da complexidade, transdisciplinaridade como perspectivas teórico-epistemológicas transcende os conceitos de compreensão acerca da Educação." (Mallart, 2008, p. 240).

Nas reflexões, todas as estagiárias dos projetos interdisciplinares afirmaram que as aulas foram desenvolvidas com atividades práticas e criativas. Seguem os relatos de duas estagiárias (A e C):

Durante as aulas que eu ministrei na minha regência na sala de aula, entendi que não adianta você ter só o pensamento criativo, você tem que agir [...]. Eu acredito que, quando a pessoa se dispõe a fazer, ela já está tendo um ato criativo, ela se dispõe a fazer e tenta melhorar a cada dia. Assim eu busquei parceria, junto à professora titular da disciplina, para promover ali com os colegas da escola ações mais criativas.

... uma das atividades criativas que os alunos viram em um primeiro momento, que foi muito boa, que eles gostaram muito, foi quando trabalhamos com as vogais, números e encontros vocálicos, eles faziam as atividades e ao mesmo tempo faziam artes com as letras, e os números de 0 a 09 foi bem interessante, porque resolvemos construir um jogo onde todas as crianças eram convidadas a participar: "Jogo de Quantos São". Por exemplo: eu determinava um número e o aluno teria que pegar a quantidade exata de palitos de Eva e colocar na cesta certa na parede. Percebemos que as crianças foram muito participativas e entusiasmadas para aprenderem.

Nota-se que as estagiárias procuraram sair do previamente estabelecido para inovar. Buscaram novas práticas pedagógicas, pois seu intuito era o desenvolvimento do 
ensino e da aprendizagem com a perspectiva da criatividade. Moraes e Valente (2008, p. 101) afirmam que:

“... as práticas pedagógicas precisam adotar procedimentos abertos às flutuações, ... às mudanças sempre que necessário."

A criatividade e a inovação, para Torre (2005), são dois termos que integram a visão de educação. Entretanto, não se trata de qualquer tipo de educação, mas aquela que busca desenvolver ações voltadas para os valores humanísticos, sociais, ambientais e culturais. Dessa forma, a intenção de propiciar condições de reflexões e desenvolvimento criativo se configura na concepção que Suanno (2013a, p. 31) apresenta, ao afirmar que:

“... a criatividade e capacidade crítica aliadas, no dia a dia, são grandes diferenciais para o surgimento de ações inovadoras..."

Observa-se também que as estagiárias, ao buscarem parcerias com as professoras titulares das disciplinas, trabalham com o intuito de ver seus educandos participativos, desenvolvendo as habilidades propostas para cada ano/série e transformando-se como sujeitos partícipes em seu contexto vivencial. Porquanto, com o apoio de toda equipe da escola, acreditam que a aprendizagem dos alunos poder ser revertida em outro cenário.

Entendemos, assim, que as atividades criativas dos respectivos projetos interdisciplinares propiciaram uma afetiva e efetiva aprendizagem. Isso porque possibilitaram as estagiárias avançar em uma compreensão que está além da proposta docente e do referencial teórico das disciplinas cursadas. Tais atividades permitiram, por conseguinte, ultrapassar o nível de repetição e favoreceram o sentido e o sentimento de autoria do processo de construção e desenvolvimento de sua própria aprendizagem e aprendizagem dos seus alunos.

Outra discussão no grupo focal diz respeito às contribuições dos projetos interdisciplinares desenvolvidos no estágio curricular no "Projeto de Extensão Interação Universidade e Escola" para a formação de futuros professores. Conforme relatos das estagiárias, a experiência por meio de projetos interdisciplinares se constitui como uma via de possibilidade de formação dos futuros professores:

Então, entendo que o projeto favoreceu muito minha atuação como estagiária e futura professora, porque estamos caminhando para a interdisciplinaridade em nossas práticas pedagógicas. Até os professores questionam muito, porque nos diários... tem que registrar separado,... em uma aula de Português elas conseguem envolver um conteúdo de Ciência, de História, Geografia, um tema transversal e, na hora do registro..., tem que ficar dividindo.

Bastante influência dos projetos na prática das aulas nossas, enquanto estagiárias, muitas mudanças, muitas mesmo, porque passamos a perceber que 
não é somente o ensino formal, mas existem... além, que seria a questão dos valores.... Não fica somente no conteúdo [projeto/aula que preparamos], extrapola, vai mais além do conteúdo... sempre me preocupei muito, muito com a questão de não ficarmos somente na questão da aula tradicional, mas irmos mais além, para sermos bons profissionais e formarmos excelentes cidadãos.

A experiência vivida através da prática em sala de aula durante o estágio curricular, no projeto de extensão, me mostrou claramente o que significa ser professor e a importância que o planejamento tem na nossa profissão, saber como explicar determinado conteúdo ao aluno, que um texto, como a história dos "Da Joaninha Diferente", por exemplo, pode ser usado como eixo temático para trabalhar, além da leitura, Geografia, Ciências Naturais (meio ambiente). Pois é no estágio curricular em sala de aula que o futuro professor tem a oportunidade de se aperfeiçoar, para exercer com êxito sua futura profissão.

Nessa perspectiva, observa-se que projetos com metodologias diferenciadas podem propiciar à sala de aula um ambiente de diálogo, dinâmico, prazeroso, onde cada descoberta é vivenciada como uma ação que educa, transforma uma realidade e propicia crescimento (Suanno, 2015), pois os alunos tornam-se protagonistas da construção de seus próprios conhecimentos, sentindo-se capazes e valorizados em seu cenário educativo.

Observa-se que o Projeto Interação Universidade Escola é um projeto integrador que potencializa e visa agregar e interligar diferentes contextos e dimensões. Para Torre (2012, p. 134), projetos com esse olhar:

“... potencializam o desenvolvimento da consciência ambiental e social, a autonomia, a criatividade, a colaboração, a dimensão emocional, em suma, a polivalência de estratégias didáticas."

Assim, esse projeto de extensão, com um olhar interligador, possibilitou uma prática transdisciplinar que oportunizou às estagiárias uma iniciativa:

“...flexível, aberta e criativa, para a leitura e interpretação do que há em seu ambiente, através de óticas diferentes e pouco usuais, mas que são necessárias para conseguir uma formação completa" preparando o aluno para a vida (Pujol, 2009, p. 84).

A outra parcela de dados, coletados por meio das entrevistas com as coordenadoras de Estágios Supervisionados (UFT) e a coordenação pedagógica da Escola Municipal Benedita Galvão, apresenta como aspecto marcante a formação continuada no trabalho interdisciplinar, na formação inicial (pedagogos) e na formação continuada de professores em exercício na respectiva escola. 
Os relatos da coordenação de Estágios Supervisionados do curso de Pedagogia ratificam a sustentabilidade da formação inicial (pedagogos) e formação continuada (professores da escola) no desenvolvimento de projetos interdisciplinares no estágio curricular, conforme segue:

Então, esse projeto desenvolvido na escola 2016, que a gente chama de "Programa de Interação Universidade e Escola", esse curso a gente reúne os professores da escola para pensar a escola, pensar os problemas da escola e os desejos que esses professores têm e as necessidades que eles têm para serem capacitados. Esse é um movimento formativo, porque a formação ocorre num contexto, na convivência humana, no diálogo, em uma participação como uma intenção pedagógica, com o objetivo de transformar as práticas dos professores da escola, e formar as alunas que estão desenvolvendo ações do estágio curricular do curso de pedagogia. Por ser um projeto inter/transdisciplinar, após a definição dos seus objetivos gerais, o desafio consiste em articular as diferentes disciplinas do quarto ano de Pedagogia. Ou seja, construir uma oficina que permitisse o diálogo entre as diferentes disciplinas e, ao mesmo tempo, avançar no reconhecimento de outros saberes, no sentido de se atingir os objetivos comuns estabelecidos para formação inicial (estagiárias) e formação continuada para os professores da escola.

... E se esta formação é interdisciplinar, o foco, é a gente pegar os conteúdos trabalhados nas diversas disciplinas, a partir da problematização, e a gente começa a abrir várias dimensões em torno dos conteúdos. Então, “como é que eu posso discutir com o aluno esses temas do ponto de vista político, e no ponto de vista econômico, e do ponto de vista cultural e do ponto de vista estético? Como é que a literatura, a música, a escultura já retrataram este tema?". Do ponto de vista local, tem notícias jornalísticas vinculadas a estes temas, a partir de todas as disciplinas, do ponto de vista planetário, tem alguma coisa ocorrendo? Então a transdisciplinaridade é uma pulsão religadora, a transdisciplinaridade é um desejo de religar percepções e conhecimentos em torno de um tema, para a gente pensar esse tema com mais fatores, com mais aspectos a serem levados em consideração.

... Entendeu-se, desde o início, que o desafio de pensar complexo, como proposto por Edgar Morin, demandava abertura, diálogo, problematização, planejamento e estudo. O desafio inicial era promover, favorecer e manter o diálogo sobre os conteúdos entre os professores universitários, as estagiárias e as diferentes disciplinas do quarto ano de Pedagoga.

Dessa forma, com essa proposta interdisciplinar compreende-se que as atividades humanas, ligadas à produção de conhecimentos, estão relacionadas diretamente à dimensão humana e sua subjetividade. A interdisciplinaridade é, pois, 
uma atividade que se apresenta como complementaridade epistemológica da pesquisa e para a compreensão das transformações por que passam as sociedades contemporâneas.

Observamos nos relatos da coordenação pedagógica da escola que a experiência desenvolvida na instituição em 2016 tornou-se referência exitosa para formação continuada de professores, como demonstra o depoimento sobre a formação continuada do professor na escola:

Então, parceria universidade escola é fundamental, porque uma coisa é você ter um projeto no papel, outra coisa você desenvolver ele na íntegra e ver o resultado, a avaliação. Então, assim, a parceria é fundamental, com os professores, com a universidade. Os alunos, os estagiários - a escola abre espaço para os estagiários, então junta os estagiários com os professores da escola - são capacitados pelos professores do curso de pedagogia da UFT.

... Muda tudo, muda porque o corpo docente da escola, ele sai daquela visão de micro, para macro. Ele começa a ser exigente com os próprios conteúdos que ele vai trabalhar. Então as atividades são desenvolvidas a partir de um texto, você extrai do texto, cada um na sua área, o tema e o que você pode trabalhar dentro da sua área, ou de sua disciplina.

Percebemos, a partir desses relatos, a visão que as estagiárias e a equipe coordenadora do estágio curricular têm em relação ao outro, à formação integral do sujeito e à educação como um todo. Mesmo que alguns ainda confundam a transdisciplinaridade com a interdisciplinaridade, são educadores que já agem transdisciplinarmente, ao se preocuparem com o bem-estar interior e exterior dos que estão em seu entorno, utilizando um olhar que vai além do pensamento reducionista e, principalmente, valorizando projetos como meios interligadores de diversos saberes.

Acerca disso, afirma Morin (2009, p. 21) que:

“... o pensamento contextual busca sempre a relação de inseparabilidade e as inter-retroações entre qualquer fenômeno e seu contexto, e desde com o contexto planetário"

Ou seja, é um pensamento interligador que parte de atitudes, que reconhece o todo como importante para a compreensão dos movimentos no cenário de aprendizagem.

Acreditamos, com base nas experiências de projetos formativos interdisciplinares desenvolvidos por meio da docência compartilhada entre universidade e escola, que a epistemologia da complexidade, nutrida de uma metodologia transdisciplinar, pode transformar-se em um fio condutor de uma nova proposta de formação inicial e continuada de professores. 


\section{Conclusões}

Nossa reflexão sobre o processo de pesquisa realizado leva à compreensão de que o trabalho didático desenvolvido no Projeto Interação Universidade e Escola do Curso de Pedagogia (UFT) e a Escola Municipal Benedita Galvão consistiu em auxiliar os educandos na relação com o conhecimento e na mediação entre sujeito, objeto, realidade e consciência que se constrói por interações intrassubjetivas e intersubjetivas (Moraes, 2008, p. 124).

Esse projeto, fruto de um esforço coletivo, se propôs a ser uma nova estratégia, um projeto de extensão inter/transdisciplinar em busca das reflexões sobre estagio curricular, formação inicial e continuada de professores e ações de cooperação entre universidade e escola, com ações sustentáveis que iniciam na ampliação da consciência do sujeito, no ser em sua convivência consigo mesmo, com o social e ambiental. A partir da percepção de que o ser humano é, também, natureza entende-se que ele modifique a relação homem-natureza-sociedade e modifique a si próprio. Em outras palavras, propiciou-se a compreensão de que estamos todos conectados e, nesse sentido, é necessário entender o outro em nós mesmos, nos identificando e nos percebendo, atentos ao respeito à diversidade.

Com base nesse entendimento, o trabalho de estágio curricular foi organizado em um processo de ensino interdisciplinar articulado com a pesquisa e com a extensão. Considera-se que o ensino com pesquisa demanda a problematização, a investigação, o estímulo à discussão, o desenvolvimento de metodologias de busca, de construção de conhecimentos e a resolução de problemas. E o ensino com extensão demanda ação com a comunidade local, mobilização de visões inter e transdisciplinares sobre o fenômeno, para, assim, possibilitar o pensar complexo, o enfrentamento de problemas sociais, ambientais, institucionais e quem sabe a indicação de potenciais caminhos para políticas de formação do professor.

Assim, acreditamos que a inter/trandisciplinaridade busca conciliar interesses da convivência humana e como prática de vida pode contribuir para mudar o campo educacional, em prol de uma educação mais humana, que considere a globalidade e a especificidade de cada sociedade.

\section{Referências}

Arnt, Rosamaria de Medeiros (2012). Cenários transdisciplinares na formação inicial de professores. Goiânia: Ed. PUC Goiás, Liber Livro Editora.

Barreiro, Iraíde Marques de Freitas e Gebran, Raimunda Abou. (2006). Práticas de ensino: elemento articulador da formação do professor. In: Iraíde Marques de Freitas Barreiro e Raimunda Abou Gebran. Prática de ensino e estágio supervisionada na formação de professores. (pp. 27-35). São Paulo: Avercamp.

Brasil. Conselho Nacional de Educação (2002). Parecer CNE/CP 21/2001. Dá nova redação ao Parecer CNE/CP 21/2001, que estabelece a duração e a carga horária dos cursos de Formação de Professores da Educação Básica, em nível superior, curso de licenciatura, de graduação plena. Diário Oficial [da] União. Brasília: MEC. 
Gil, Antônio Carlos (2002). Como elaborar projetos de pesquisa. 4a. ed. São Paulo: Atlas.

Gil, Antônio Carlos (2008). Métodos e técnicas de pesquisa social. $6^{\text {a }}$. ed. São Paulo: Atlas.

Lima, Maria Socorro Lucena (2012). Estágio e aprendizagem da profissão docente. Brasília: Liber Livro.

Mallart, Joan (2008). Ecoformação: além da educação ambiental. In: Saturnino de la Torre, Maria Antônia Pujol Maura e Maria Cândida Moraes (Org.). Transdisciplinaridade e ecoformação: um novo olhar sobre a educação. (pp. 235-260). São Paulo: Triom.

Pujol, Maria Antonia (2009). Educação infantil como estado permanente da criatividade. In: Marlene Zwierewicz e Saturnino de la Torre (Coord.). Uma escola para o século XXI: escolas criativas e resiliência na educação. (pp. 7185). Florianópolis: Insular.

Melo, Kênia Abbadia de (2011). Pensamento complexo: uma nova e desafiadora forma de pensar a educação a partir das ideias de Edgar Morin. In: IV Encontro Estadual De Didática E Prática De Ensino - EDIPE. Anais... Goiânia: PUC GO.

Moraes, Maria Cândida e Valente, José Armando (2008). Como pesquisar em educação a partir da complexidade e da transdisciplinaridade? São Paulo: Paulos.

Morin, Edgar (2000). Os sete saberes necessários à educação do futuro. Tradução de Catarina Eleonora F. da Silva e Jeanne Sawaya. 2a . ed. São Paulo: Cortez, Brasília: Unesco.

Morin, Edgar (2001). Introdução ao pensamento complexo. $3^{\mathrm{a}}$. ed. Lisboa: Instituto Piaget1.

Morin, Edgar (2007). Desafios da transdisciplinaridade e da complexidade. In: AUDY, Jorge Luís Nicolas Audy e Marília Costa Morosini (Org.). Inovação $e$ interdisciplinaridade na universidade. (pp. 22-28). Porto Alegre: EDIPUCRS.

Morin, Edgar (2009). Educação e complexidade: os sete saberes e outros ensaios. In: Maria da Conceição de Almeida e Edgar de Assis Carvalho (Org.). Educação e complexidade: os sete saberes e outros ensaios. Tradução de Edgar de Assis Carvalho. $5^{\text {a }}$. ed. (pp. 1-104). São Paulo: Cortez.

Morin, Edgar (2011). Os sete saberes necessários à educação do futuro. São Paulo: Cortez, Brasília: Unesco.

Morin, Edgar (2015). Ensinar a viver: manifesto para mudar a educação. Tradução de Edgar de Assis Carvalho e Mariza Perassi Bosco. Porto Alegre: Sulina.

Pimenta, Selma Garrido e Lima, Maria Socorro Lucena (2004). Estágio e docência. São Paulo: Cortez.

Suanno, Marilza Vanessa Rosa (2014). Em busca da compreensão do conceito de transdisciplinaridade. In: Maria Cândida Moraes e João Henrique Suanno (Org.). O pensar complexo na educação: sustentabilidade e criatividade. (pp. 45-58). São Paulo: Wak.

Suanno, Marilza Vanessa Rosa (2015). Didática e trabalho docente sob a ótica do pensamento complexo e da transdisciplinaridade. 2015. $493 \mathrm{f}$. Tese (Doutorado 
em Educação) - Programa de Pós-Graduação em Educação. Brasília: Universidade Católica de Brasília - UCB.

Suanno, João Henrique (2013a). Adversidade, resiliência e criatividade: uma articulação oportuna? In: Mariza Vanessa Rosa Suanno, Maria Glória Dittrich e Maria Antônia Pujol Maura (Org.). Resiliência, criatividade e inovação: potencialidades transdisciplinares na educação. (pp. 31-42). Goiânia: Ed. UEG; América.

Suanno, João Henrique (2013b). Escola criativa e práticas pedagógicas transdisciplinares e ecoformadoras. Tese (Doutorado em Educação). Brasília: Universidade Católica de Brasília - UCB.

Suanno, João Henrique (2015b). Transdisciplinaridade, criatividade e o terceiro incluído na formação de professores. In: Maria Aparecida Behrens e Romilda Teodora Ens (Org.). Complexidade e transdisciplinaridade: novas perspectivas teóricas e práticas para a formação de professores. (pp.107-121). Curitiba: Appris.

Suanno, João Henrique (2015b). Cooperação internacional pelas águas: metatema no Estágio Curricular do Curso de Pedagogia. In: Maria José Pinho, Marilza Vanessa Rosa Suanno, João Henrique Suanno e Elzimar P. N. Ferraz (Org.). Complexidade, interdisciplinaridade e transdisciplinaridade na educação superior. Goiânia: Espaço Acadêmico.

Torre, Saturnino de la (2005). Dialogando com a criatividade. Tradução de Cristina Mendes Rodríguez. São Paulo: Madras.

Torre, Saturnino de la e Zwierewicz, Marlene (Coord.) (2012). Criatividade na adversidade: personagens que transformaram situações adversas em oportunidade. Blumenau: Nova Letra.

i Aluna de Estágio Pós-doutoral do Programa de Pós-Graduação Interdisciplinar em Educação, Linguagem e Tecnologias - IELT - Universidade Estadual de Goiás - UEG, sob a orientação do Prof. Dr. João Henrique Suanno.

Data de recebimento: $27 / 10 / 2017$

Data da revisão: $11 / 12 / 2017$

Data do aceite: $15 / 12 / 2017$ 